\title{
O planejamento do espaço rural periurbano: da abordagem funcional do território às territorialidades da autonomia*
}

\section{Planning the periurban rural space: from functionalist approach of territory to territories of autonomy}

\author{
Nicolas FLORIANI**
}

RESUMO

O texto discute a questão da crescente demanda urbana pela preservação dos recursos naturais em áreas periurbanas. Nesse sentido, adverte-se ao fato do espaço rural periurbano caracterizar-se atualmente como um ambiente de conflito pelo uso do território, sendo concebido pelas políticas de planejamento territorial como espaço de interesses ambientais conflitantes e como espaço de risco socialmente construído. Assim sendo, evidencia a relação, muitas vezes oposta e conflituosa, entre campo e cidade, encerrando em si a contradição entre projetos de desenvolvimento econômico e de preservação ambiental. Por outro lado, aponta-se para a necessidade de um recorte espacial das práticas agrícolas, capaz de permitir o entendimento das relações entre os agricultores familiares ecológicos e a natureza, passando pelo estudo das representações e percepções da paisagem, que se expressam materialmente no território da agricultura familiar. Defende-se a idéia que tal abordagem permite pensar políticas alternativas de desenvolvimento territorial condizentes com as realidades socioambientais locais.

Palavras-chave: território; terroir; paisagem; agricultura familiar; conflitos socioambientais.

\begin{abstract}
This text discusses the issue of growing urban demand for the preservation of natural resources in periurbans territories. In that sense, warns to the fact of rural periurban space is currently characterized as an environment of conflict through use of the territory, being designed by the policies of territorial planning as an area of environmental interests and conflicting area of risk as socially constructed. Therefore, highlights the relationship, often opposite and confrontational, between city and countryside, closing

* $\quad$ Este artigo apóia-se em tese defendida pelo autor no Doutorado em Meio Ambiente e Desenvolvimento da Universidade Federal do Paraná em 2007.

** É doutor em Meio Ambiente e Desenvolvimento pela Universidade Federal do Paraná (2007), realizando parte de seu doutorado no Laboratoire Dynamiques Sociales et Recomposition des Espaces - Ladyss (Université Paris X). Atualmente é Professor colaborador no Departamento de Geociências da Universidade Estadual de Ponta Grossa (UEPG-PR) e tem se dedicado a pesquisar sobre a gestão participativa de recursos naturais, com ênfase na representação espacial e na percepção da
\end{abstract} paisagem. 
itself the contradiction between economic development projects and environmental preservation. On the other hand, points to a need to the spatial approach of agricultural practices, which can enable the understanding of relationships between family farmers and ecological nature, through the study of representations and perceptions of the landscape, which are materially expressed in the territory of family farming. It is defended the idea that this approach to suggest alternative policies of territorial development consistent with the local social realities.

Key words: territory; terroir; landscape; family farming; socioenvironmental conflicts.

\section{Alguns pressupostos implícitos nas ações de pla- nejamento dos espaços rurais periurbanos ${ }^{1}:$ a preservação dos recursos naturais em foco}

A demanda pelo uso sustentável dos recursos naturais por parte dos grandes centros urbanos tem gerado políticas impositivas pela preservação e uso dos ecossistemas em ambientes rurais periurbanos. Não obstante, as ações de planejamento e gestão ambiental do espaço rural periurbano são marcadas, grosso modo, nas regiões metropolitanas brasileiras, por duas idéias aparentemente contraditórias: da preservação dos espaços "naturais”, melhor dizendo, da preservação de suas paisagens com seus recursos; e da modernização da atividade agrícola.

De acordo com Duvernoy (2002), o que se presencia atualmente em termos de ações de desenvolvimento do espaço rural - mesmo sendo as relações cidade-campo as mais inovadoras possíveis em termos de emprego, de construção e preservação da paisagem, de patrimônio agrícola urbano, etc - são ainda as funções clássicas demandadas à agricultura pelas municipalidades.

Nos discursos das municipalidades são identificadas pela autora quatro maneiras de conceber a agricultura periurbana: como uma atividade que está em vias de desaparecimento; como uma atividade que contribui à gestão da urbanização; como uma atividade econômica; e como “zona verde” e patrimônio histórico².
Portanto, evidenciam-se representações em torno do meio rural periurbano anexadas à questão da preservação dos espaços "naturais", melhor dizendo, à preservação de suas paisagens e de seus recursos, e ao desenvolvimento das atividades produtivas. Essa maneira de conceber rural está na base da relação entre cidade e campo. Não obstante, qual é a origem e quais os pressupostos da política dita de proteção dos espaços naturais no meio rural?

Analisando a evolução das representações sociais sobre a cidade o e campo, Mathieu (1996, p.193) caracteriza sobre o plano ideal os espaços urbano e rural como entidades posicionadas de maneira oposta e conflituosa. De acordo à autora, na Europa, tanto ocidental como oriental, uma mesma e única representação social de cidade e do campo predomina desde a segunda guerra mundial: a cidade como meio técnico, e o campo como meio agrícola e natural.

Nascida da revolução industrial, a definição generalizada da cidade européia é associada àquela de tecnologia, de indústria, de progresso, de modernidade, de sociável ${ }^{3}$. Contrariamente, esta representação apresenta aspectos negativos quando pensada em relação ao meio rural. Ele é definido pelos termos inversos associados àqueles da cidade: do natural, que é preciso dominar, manejar, socializar; do agrícola, que reenvia à propriedade fundiária e do apego à terra, e assim à idéia de uma classe camponesa reacionária ou de um grupo social arcaico do ponto de vista técnico e social, cujo caráter individualista é necessário erradicar, seja coletivizando e criando um novo habitat ur-

1 Para Duvernoy (2002), as relações entre a extensão urbana e o espaço agrícola podem ser analisados como a difusão espacial de um front de urbanização em um espaço agrícola que mal resiste. Por outro lado, tal fenômeno leva também em conta o ato de uma transformação mais global dos espaços rurais (nomeado geralmente "rurbanização") nos quais a parte de ativos agrícolas diminui, e analisa-se ao contrário a periurbanização como o resultado de estratégias fundiárias dos grandes proprietários de terras, estratégias inscritas nas políticas de urbanização através de suas redes de poder.

2 Vale fazer uma pequena pausa para adicionar o que Duvernoy (2002) conclui a respeito do debate atual sobre a multifuncionalidade da agricultua. De acordo com a autora, é necessário colocar duas questões: quem define esta multifuncionalidade e de que maneira é legitimada e reconhecida? Como resposta conclusiva a autora afirma que, "atualmente, são ainda as funções clássicas que são demandadas à agricultura pelas coletividades locais, mesmo se as relações cidade-campo mais inovadoras em termos de emprego, de construção e preservação da paisagem, de patrimônio agrícola urbano parecem surgir”.

3 A partir dessa concepção de cidade deriva a idéia de "superioridade de se habitar a cidade, em um meio socialmente denso onde há crescente oferta de emprego, liberação dos homens para a escolha do trabalho, pela modernidade dos modos de vida, a disposição de todas as inovações técnicas (transporte, eletricidade, higiene, lazer)” (MATHIEU, 1996, p. 194). 
bano, seja modernizando a agricultura, promovendo a "urbanização do campo" (MATHIEU, 1996, p. 195).

Nesse processo histórico fica evidente a desvalorização do habitat rural e mesmo a negação da existência do rural não agrícola. Assim, irremediavelmente, o rural torna-se o inabitável, o não-habitado ou o habitat-temporário, cujo futuro é pensado como seu necessário ou inevitável desaparecimento ${ }^{4}$.

Até os anos 50 do século vinte, a atitude dominante no que concerne à gestão do espaço rural - assimilado abusivamente a um espaço natural - como bem grifam Bertrand e Jollivet (1980, p. 18) - era um tipo de indiferença, uma espécie de laisser-faire. Contudo, após esse período, a evolução que conhece a agricultura, a evolução da utilização dos solos, aparece fortemente ligada à exploração racional: as boas e as más terras são submetidas a apropriações diferenciadas, sendo as primeiras designadas ao cultivo de grãos e pastagem, e as segundas - de um emprego agrícola aleatório - destinadas ao abandono, visto então como uma forma de retorno ao estado "natural" das paisagens.

Concomitantemente, no final dos anos de 1960 nascem os projetos de planejamento a serem aplicados em muitos países em desenvolvimento. A finalidade era de possibilitar o desenvolvimento econômico de regiões que deveriam ser transformadas em "regiões do futuro" (em referência ao período de pujança econômica dos países desenvolvidos rápido conhecido como os “30 anos gloriosos”). Com rigor, os poderes públicos desenharam novas cartas de espaços “encaixotados”. Nascem, então, os esquemas de planejamento regional, planos diretores de planejamento e urbanismo, planos de ocupação dos solos, planejamento rural (zonas rurais), zonas protegidas, em regiões devoradas pela urbanização (FRÉMONT, 1999, p. 252).

Essa evolução da utilização do espaço rural é a primeira explicação da evolução da política do Estado em relação a esse espaço. Esse cenário, ademais, é dominado por uma inquietude generalizada quanto aos limites do crescimento econômico: ela revela a idéia que os recursos naturais estão em vias de escassearem. Aparece a idéia de que essas riquezas, longe de serem inesgotáveis, são limitadas. Inscreve-se, assim, a idéia que o destino coletivo comum depende dessas riquezas, sendo elas um patrimônio coletivo, quer dizer, um bem a ser preservado de um lado, e a ser limitado ao uso individual descontrolado e submetido às regras coletivas de utilização de outro, revelando, pois, a faceta normativa da questão ambiental (BERTRAND; JOLLIVET, 1980, p.19).

Em que pese à política ambiental do período dos anos 70 aos $90^{5}$ do século passado, o planejamento territorial continua sendo moldado pelos imperativos do desenvolvimento agrícola orientado para o aumento da produtividade da agricultura, reorganizando e gerenciando os espaços rurais (BILLAUD, 2005, p. 111).

Assim, para Billaud (2005, p. 111) a abordagem funcional do território é a chave do planejamento dos espaços rurais, produzindo com isso inúmeros efeitos: a separação radical entre os espaços produtivos e os espaços de proteção; a emergência nos anos de 1970 das noções de zona desfavorizada (ou campo marginal) e de espaços especializados como os Parques Nacionais aos quais uma relativa autonomia é deixada; a criação dos Parques Regionais Naturais; a emergência de pluriatividade (dimensão social) e de paisagem (dimensão natural).

Esta primeira fase, dos anos de 1970 aos anos de 1990, tem efeitos sobre a relação entre meio ambiente e ruralidade. Constrói-se uma imagem plural do meio ambiente, constituída de diversos ambientes: as amenidades como a paisagem, os recursos naturais que devem ser apropriados e gerenciados, de natureza cuja conservação supõe uma abordagem mais complexa que sua simples salvaguarda, os riscos que lembram a vulnerabilidade dos sistemas (BILLAUD, 2005, p. 114).

4 Nos últimos 30 ou 40 anos, a maioria das construções sociais sobre o rural sugeria o seu desaparecimento. As idéias da urbanização societária e da artificialização da agricultura constituíam o cerne deste questionamento. Em verdade, a idéia do desaparecimento do rural era até pouco tempo comum aos quadros teóricos das ciências sociais, cujo pensamento clássico pressupunha a hegemonia do industrialismo e da urbanização na civilização moderna; a substituição da comunidade pela sociedade; a racionalização do mundo como sentido dos processos sociais em curso e a generalização do modo de produção capitalista industrialista e urbana em escala planetária (FERREIRA, 2002, p. 28).

5 No contexto do pós-guerra, dominado pelo tratamento político e social da questão agrária, a questão ambiental constitui-se, no período dos anos de 1970 aos de 1990, em matriz dos limites do projeto agrícola, colocando em dúvida sua capacidade de conter em si a trajetória dos espaços rurais, isto é, apresentando-se como um obstáculo ao projeto modernizador da agricultura. Assim, o desafio ambiental emerge no conjunto da sociedade francesa. Contudo, a ruralidade é ainda particularmente marcada, em matéria de proteção da natureza, pela concepção colbertiana - ministro de Louis XIV que na época elabora uma lei a fim de reservar a floresta de domínio do Estado à produção de madeira para Marinha nacional - de proteção florestal que restringe os espaços essenciais de reprodução do pequeno agricultor ao apropriarse de golpe dos recursos naturais de suas propriedades. (BILLAUD, 2005, p. 112). 
Não obstante, conforme o mesmo autor, a reconfiguração dos espaços rurais continua subordinada aos imperativos do dispositivo agrícola da modernização ${ }^{6}$, isto é, do conjunto subordinado de práticas, de enunciados científicos, e de instituições que tratam da questão agrícola. O tratamento da natureza se inscreve, portanto, no projeto moderno a partir da separação radical, no planejamento dos territórios, entre espaço de produção e espaço de proteção, participando da instauração da grande separação entre sociedade e natureza, tão típica da modernidade ocidental.

Evidencia-se, nesse contexto, a questão da normatização das atividades e a emergência de novos territórios ambientais (BILLAUD, 2005), isto é, da territorialização dos elementos da paisagem a partir da instauração de instrumentos da política de planejamento e gestão ambiental fundamentados na 'falácia preservacionista’ dos espaços naturais. As áreas de proteção ambiental (APAs), em que pese os fortes argumentos científicos sobre a necessidade de sua conservação, afetam, contudo, diretamente os interesses dos agricultores, em especial a reprodução social dos agricultores familiares (ZANONI et al., 2000).

Casos como da Região Metropolitana de Curitiba e de Guaraqueçaba, litoral norte do Paraná, mostram como a proteção ambiental, tal como tem sido realizada em muitos espaços brasileiros, pode se contrapor a um desenvolvimento rural - ou mesmo territorial " que contemple as necessidades das populações locais, gerando conflitos de uso dos recursos e de significados sobre o que é a preservação da natureza, e abrindo caminho para um ambiente rural gerido por mecanismos de fiscalização e repressão (BRANDENBURG et al., 2004, p. 121-122).

De acordo a Jollivet (1997, p. 356), há uma imposição dos interesses da sociedade urbano-industrial ao meio rural de políticas de proteção dos ecossistemas. Este tipo de conflito pela apropriação do espaço, segundo o autor, reaviva um eventual antagonismo cidade-campo enfocado pelas políticas de planejamento que tomavam em conta as necessidades das populações urbanas e que se traduziam em sentimentos negativos para as populações rurais:

[...] trata-se ainda da concepção de utilização do espaço rural - que comporta a mistura entre a defesa de interesses individuais (ligados à propriedade privada), entre os direitos de usos coletivos, meio de vida, etc, - [em oposição] às concepções ideológicas fundamentais sobre o tipo de sociedade [urbano-industrial] desejada.

Hoje, e na maior parte do tempo, sob a pressão dos movimentos ecológicos estes conflitos têm tomado uma conotação ambientalista, com a qual mistura-se uma concepção protecionista da natureza que foi qualificada como 'conservacionista'7, a partir do momento que há uma ruptura mais ou menos radical com o modo de desenvolvimento dominante.

Através da referência ambiental, pelo seu projeto e senso que ela veicula, uma categoria nova de rural começa a tomar corpo: torna-se, dentre outras formas de mutação ${ }^{8}$, o lugar de aplicação da doutrina ambientalista planetária à medida que é representado como reserva de recursos naturais (água, solo, ar, biomassa) e isto se traduz em um conjunto de regulamentações sobre o uso destes recursos, tornando-se espaços protegidos por meio da imposição legal. Esta mudança na representação coletiva do rural exprime uma tentativa de restabelecer a existência de uma verdadeira fronteira entre a sociedade (cultura) e a natureza, na qual a ação humana pode ser barrada no momento que se revela capaz de explorar a totalidade da esfera natural (JOLLIVET,1997, p. 361).

6 O dispositivo agrícola da modernização é visto por Hoeffle et al. (2002) com um modo de transferência de tecnologia de países industrializados para países nãoindustrializados, num modelo de difusão autoritária e centralizadora “de cima para baixo” e “de centro para a periferia”, da indústria para a agricultura e da cidade para o campo. Para o recebimento desta tecnologia era necessário um programa educativo, disseminando entre os produtores uma visão científica e homogênea do mundo e da agricultura, ajustando comportamentos locais às novas tecnologias, tornando os produtores elementos receptivos e passivos. As tecnologias também uniformizavam o espaço, ajustando-se a qualquer ambiente e tornando o homem independente da natureza que passa a ser controlada e planejada conforme seu potencial produtivo.

7 A região norte do litoral paranaense mostar-se como um caso emblemático: na APA de Guaraqueçaba a política ambiental instaurada revela contradições marcantes no que diz respeito ao processo de imposição de leis coercitivas no meio rural.

8 Com relação às mutações do rural na sociedade ocidental moderna, Jollivet (1997, p. 361) aponta cinco tipos: a) o rural destacando-se do agrícola; b) a agricultura destacando-se do rural; c) o campo deixado de ser identificado a um ambiente de qualidade (vítima de agressões poluentes vindas do exterior); d) o rural tornando-se um simples espaço disponível às estratégias de localização (seja de habitat ou de atividade) e; e) o rural tornando-se o lugar de aplicação da doutrina ambientalista planetária. 
Ora, a questão da preservação dos espaços naturais responde segundo Bertrand e Jollivet (1980), à propensão tecnocrática e naturalista de isolar a Natureza da Sociedade. Tal problemática pode ser abordada sob diversos ângulos, isto é, sob o plano da linguagem e dos conceitos: o mito da naturalidade, o mito da espacialidade, o mito da proteção.

Nesse sentido, o tratamento da natureza se inscreve no projeto moderno da separação radical entre o espaço de produção e espaço de proteção, participando da instauração da grande separação entre sociedade e natureza, presente nas legislações ambientais e nas metodologias de avaliação das paisagens, fazendo parte do arcabouço instrumental das ações de planejamento e gestão dos espaços rurais 9 .

Não obstante, as entidades de planejamento territorial ainda utilizam o estereótipo dos 'espaços naturais intocados pelo homem' para afirmar outros elementos, em particular de ordem sociológica: o interesse pela proteção dos espaços naturais é um assunto que não deve passar pela análise das formas de proteção da 'Natureza', mas pela reflexão sobre os fenômenos de urbanização dominante e galopante, inscrevendo-se, portanto, na relação urbano-rural. Tal análise deve basear-se no estudo das relações desiguais entre dois tipos de organização do espaço que não utilizam os elementos naturais da mesma maneira (BERTRAND; JOLLIVET, 1980, p. 8).

A idéia de salvaguardar os espaços qualificados como naturais não é senão uma maneira de responder à crise atual do mundo rural. Concomitantemente, esta crise representa o sucesso da revolução urbana e industrial que marca, por sua vez, o desmantelamento dos agroecossistemas tradicionais que se situam na periferia do sistema econômico dominante e são cada vez mais marginalizados ou submetidos às especulações não agrícolas que agravam geralmente sua desorganização.
Paradoxalmente, é possível constatar nos territórios periurbanos em disputa, cenários incongruentes no que tange às práticas socioespaciais: se por um lado existem ações impositivas pela preservação dos recursos naturais - mesmo que isso leve à desestruturação de agroecossistemas tradicionais - por outro, constata-se a expansão de formas de produção agrícola subordinadas exclusivamente aos imperativos do mercado ${ }^{10}$.

Como bem dizem Bertrand e Jollivet (1980, p.11), a idéia de "espaços naturais é uma apelação científica imprópria e socialmente perigosa na medida em que ela mascara uma parte da realidade: a dimensão social do espaço rural produtivo”. Esses autores já se referiam, no início da década de oitenta do século 20, a uma evolução em grande velocidade e em sentidos muito diferentes desses espaços abandonados ou em vias de abandono, geralmente muito parcelados, nos territórios periurbanos franceses. E caracterizaram tal fenômeno como a disfunção entre as porções do território, isto é, a disfunção entre o ecológico e o social.

Para tanto, segundo os mesmos autores, seria imprescindível situar a política de planejamento territorial, que não poderia se reduzir de maneira alguma à salvaguarda de alguns espaços em nome do patrimônio ecológico ou cultural (BERTRAND; JOLLIVET, 1980, p.12-13).

É necessário entender que este jogo de interesses, marcado pelas políticas ambientais de caráter controlador e de proteção do ambiente natural, se expressa na demanda social por um meio ambiente "intocado" (mitificado), não alterando necessariamente os rumos de um estilo de desenvolvimento centrado no consumismo e em um padrão de vida inscritos num sistema que privilegia o expansionismo ilimitado da racionalidade.

Ou seja, os indicativos mostram ser possível tratar da questão ambiental mantendo e conservando um sistema

9 Mesmo com o forte apelo da gestão participativa e sustentável do uso dos recursos naturais nos projetos de criação de áreas de preservação ambiental, quando aplicados ao estudo dos impactos ambientais, esses recortes analíticos tendem, pois, a restringir outras formas de uso dos recursos naturais que escapam à lógica da exploração agrícola convencional - produtivista -, isolando os ecossistemas frágeis em um lado e os de alto potencial produtivo em outro (o autor, 2007).

10 Segundo Saquet (2007, p. 172), as dimensões sociais do território (a economia, a política e a cultura) estão no mesmo nível. Porém, ora uma(s), ora outra(s) dimensão(ões), em cada lugar e momento e/ou período histórico, pode(m) predominar diante das demais. Nesse sentido, o território periurbano da porção setentrional da região metropolitana de Curitiba, vem presenciando os seguintes fenômenos espaciais ligados ao exacerbamento da dimensão econômica com suas conseqüências sócioambientais: a) a substituição de áreas de agricultura (temporária e permanente) e de pastagem natural pela implantação de grandes projetos de reflorestamento com monoculturas de plantas exóticas como o pinus - fenômeno, incentivado pelas medidas fiscais e amparadas pelas políticas de uso do solo agrícola; b) a expansão de olericultura intensiva baseadas no modelo produtivo convencional em áreas de susceptibilidade erosiva potencial ou de contaminação dos recursos hídricos; c) a perda de áreas agrícolas limítrofes ao movimento expansivo da urbanização, a qual tem ocorrido sobre terras de boa qualidade agrícola e também sobre áreas florestadas. 
social que, ao privilegiar a racionalidade técnico-econômica, em nada alteraria sua lógica de funcionamento (BRANDENBURG, 1999, p.79)

Impõem-se, na perpetuação desse jogo de interesses, a criação de unidades de conservação (áreas de preservação florestal e também a previsão da conversão dos sistemas de produção convencionais vigentes em sistemas produtivos teoricamente menos impactantes aos ecossistemas) como forma de garantir a apropriação à população urbana (regional, nacional e internacionalmente) dos recursos naturais locais.

Assim, seguindo essa lógica, "surgiria a natureza [paisagem] reconstruída dos campos abandonados e vazios, com áreas reflorestadas pelas indústrias que cultivariam fontes e energia renováveis, ou com áreas de lazer transformadas em museus naturais para o privilégio de poucos" (BRANDENBURG, 1999, p.80).

Por outro lado, os agricultores familiares há muito tempo instalados nesses territórios periurbanos, como é o caso da Região Montanhosa do Açungui, ao norte de Curitiba, carecem historicamente de assistência social e de políticas públicas de desenvolvimento rural, mas que de igual maneira são cobrados por aquelas instituições pela preservação dos recursos naturais.

\section{A territorialidade da agricultura familiar ecoló- gica $^{11}$ : outra pespectiva para conservação das paisagens em espaços rurais periurbanos}

Segundo Vargas (2006), citando Shneider, o enfoque territorial tem um significado muito relevante nas diferentes perspectivas analíticas que trabalham o tema do desenvolvimento rural ${ }^{12}$. O território, nessa nova perspectiva, passou a figurar como importante unidade de análise dos problemas das ações políticas sobre o espaço, levando-se em conta o esgotamento teórico e prático da abordagem regional (a noção planejamento regional) como unidade de referência para se pensar as ações e políticas públicas voltadas ao desenvolvimento rural.

Nesse sentido, esse rural contemporâneo é um rural que começa a ser pensado como territórios do futuro, como resposta possível à crise do emprego e da qualidade de vida gerada pela civilização urbano-industrial. Tais territórios apresentam-se opostos à posição teórica da homogeneização do rural, surgindo como posição da reconstrução e ressignificação do mesmo. Segundo esta visão, o rural aparece como um espaço de vida e trabalho, uma rede de relações sociais, uma paisagem ecológica e cultural e representações específicas de pertencimento, de desejo ou projetos de vida (FERREIRA, 2002).

O rural ressignificado exige a construção de novas identidades (territorialidades), a partir da valorização de outras dimensões do território que não somente a econômica. Assim, é fundamental destacar valores subjugados pela racionalidade econômico-instrumental implícita nos planos de desenvolvimento do espaço rural: os saberes locias produzidos localmente.

Assim, o reconhecimento de outros saberes que não científicos pode emergir significativamente a partir das trocas entre as formas de apropriação de uma dada organização social com o seu território, sendo que o que irá diferenciar os diversos tipos de relacionamento entre as atividades humanas e o seu ambiente, é o grau de desenvolvimento técnico dos instrumentos de produção criados pela capacidade produtiva da organização sociotécnica e econômica de uma determinada sociedade (FLORIANI, 2007, p. 108).

\footnotetext{
11 Considerando as várias correntes da agricultura ecológica hoje praticada, verifica-se que há um processo de mudança em curso no padrão técnico produtivo. No lugar da universalização técnica da produção conforme previa a modernização conservadora, surgem modelos alternativos que buscam na gestão dos recursos naturais a sua base fundamental. Essa ecologização da base técnica de produção está presente em todas as correntes, embora com especificidades no que tangem aos métodos e práticas sociais e produtivas. Nesse sentido, assumimos como Agricultura de Base Ecológica a prática social que integra os princípios de produção baseados em tecnologias ecológicas; de valorização do conhecimento tradicional; de policultivos e produção para autoconsumo, de integração da produção animal e vegetal; de cooperação entre os agricultores; de intervenções no mercado; de certificação participativa e de agroindustrialização da produção, e que se expressa em sua maior plenitude na agricultura familiar ecológica que pode ser o instrumento de busca de agriculturas sustentáveis e mesmo de um processo de desenvolvimento sustentável (MAGNANTI apud ZONIN et al., 2006).

12 A abordagem territorial é um caminho para se compreender as relações e complementaridades que acontecem entre os espaços urbano e rural, seus conflitos, as redes, as relações de poder, enfim a unidade rural-urbana no ambito da relçaão economia-política-cultura e natureza e das tramas territorias: há um processo contínuo de urbanizaão do espaço rural e/ou desconcentraç ]ao; formas de ligação campo-cidade; modernização agrícola; redes e fluxos materiais; integração contratual; cooperativas; assentamentos; circulação simples de mercadorias; as migrações pendulares, etc (SAQUET, 2007, p. 160).
} 
Nessa perspectiva, ainda aponta o autor que o que está em jogo também é a possibilidade de acesso a uma racionalidade ambiental que possa superar ou preencher os vazios deixados pelo desconhecimento das ciências, na direção de um novo saber ambiental.

Nesse sentido, ao se pensar um planejamento do uso dos recursos naturais deve-se seguir uma racionalidade ambiental que inclua novos princípios teóricos e novos meios instrumentais para reorientar as formas de manipulação produtiva da natureza. Cabe lembrar que essa nova racionalidade está sustentada por valores (qualidade de vida, identidades culturais, sentidos da existência) que não aspiram a alcançar um status de cientificidade. Abre-se dessa forma um diálogo entre ciência e saber, tradição e modernidade (LEFF, 2001).

O meio rural, por sua vez, possui suas particularidades e - utilizando as palavras de Wanderley (2000) - pode ser entendido como

[...] um espaço suporte de relações sociais específicas, que se constroem, se reproduzem ou se redefinem sobre este mesmo espaço e que o conformam, portanto, enquanto um singular espaço de vida. Para compreendê-lo é preciso considerar sua dinâmica social interna, isto é, aquela que resulta da maior ou menor intensidade e complexidade da vida local [...] (WANDERLEY, 2000, p. 30)

Sendo assim, o meio rural suporta relações sociais específicas que o constroem e o transformam em um espaço de vida singular em função dos laços de parentesco e de vizinhança, tanto ao nível da vida cotidiana quanto ao ritmo dos acontecimentos que determinam o ciclo de vida familiar, cultural e religiosa.

Esse espaço é habitado e transformado pela agricltura familiar que o torna seu lugar (no sentido topofílico do termo), isto é, dando-lhe um sentido de pertencimento ao lugar da família centrado em torno do seu patrimônio - lugar de convergência e referência (WANDERLEY, 2000, p. 30).

Categoria social vinculada a uma unidade de produção agrícola onde propriedade e trabalho estão intimamente ligados à família, a agricultura familiar é depositária de uma cultura cuja reprodução é necessária para dinamização tecno-econômica, ambiental e social do meio rural (LAMARCHE, 1993; WANDERLEY, 2000).

A agricultura familiar guarda ainda muito dos seus traços camponeses. Esta forma tradicional de agricultura tem particularidades que a especificam no interior do conjunto maior da agricultura familiar e que diz respeito a um modo específico de produzir e de viver em sociedade e à forma de inserção na sociedade global (WANDERLEY, 1996, p. 3).

Cinco traços característicos das sociedades camponesas são identificados por Henri Mendras, citado por Wanderley (1996, p. 3), a saber: i) uma relativa autonomia face à sociedade global; ii) a importância estrutural dos grupos domésticos; iii) um sistema econômico de relativa autarcia; iv) uma sociedade de interconhecimentos e; v) a função decisiva dos mediadores entre a sociedade local e a sociedade global.

Com relação a influência da comunidade na configuração da cultura tradicional e do modo de vida camponês, Mendras citado por Abramovay (1992, p. 109) diz que

[...] é nos limites da comunidade que se opera o essencial da socialização camponesa [...] O camponês vive toda a sua vida e todos os aspectos desta em uma coletividade local pouco numerosa que é uma sociedade de interconhecimento, isto é, ele ai conhece todo mundo e todos os aspectos da personalidade dos outros.

Explicando a característica dessa sociedade de interconheciemento do campesinato, Wanderley (1996, p. 07). afirma que a agricultura camponesa tradicional é profundamente inserida em um território, lugar de vida e de trabalho, onde o camponês convive com outras categorias sociais e onde desenvolve uma forma de sociabilidade específica, que ultrapassa os laços familiares e de parentesco.

De acordo a Abramovay (1992, p. 101) o ambiente social no qual se funda o campesinato permite que outros critérios de relações humanas (além dos econômicos) sejam organizadores da vida. Apoiado em Galeski, o referido autor destaca a capacidade do campesinato estruturar a vida social em torno de um conjunto de normas próprias e específicas: vida em comunidade, vínculos personalizados entre os indivíduos e agentes sociais, regras coletivas determinantes do uso dos fatores produtivos e do consumo, são influenciados pela regras comunitárias e pela família.

Nesse sentido, a família e a comunidade dão sentido à atividade camponesa, guiando a unidade de produção a "gerar não só os meios de vida, mas sobretudo um modo de vida", cujos significados aderidos aos elementos do trabalho incorporam representações de que a "ter- 
ra não é um simples fator de produção [...]" (ABRAMOVAY, 1992).

Esse reencontro das dimensões materiais e imateriais da natureza transformada pelo pensamento em toda sua realidade - consciente e inconsciente, individual e coletiva - para citar as reflexões de Godelier ${ }^{13}$, encontra ambiente fértil também nas explicações sobre a relação territórioterritorialidade.

Ao admitirmos como válida a definição de territorialidade proposta por Magnaghi (apud SAQUET, 2007, p. 148); ou seja, “como um código genético local, material e cognitivo; produto social da territorialização que se constitui em patrimônio territorial de cada lugar [...], no qual há uma co-evolução social e natural”, então esse processo (a territorialidade) implica, segundo Godelier (1984, p. 15):

[...] em um processo de adaptação dos homens que demanda desde o começo a elaboração das representações de interpretações da natureza partilhadas pelos membros de uma coletividade, isto é, a organização das diferentes formas de intervenções individuais e coletivas sobre a natureza que leva em conta as percepções individuais e coletivas.

Partindo do enfoque das representações geográficas busca-se, então, uma leitura interiorizada sob a ótica do cotidiano vivido pelos grupos humanos, levando à compreensão dos sistemas de valorização e territorialidade correspondentes, e, por meio das subjetividades, viabiliza a seleção de elementos importantes para o estabelecimento das regiões. Nesse sentido, os estudos regionais devem evidenciar muito mais que os recortes apresentados, pois ao descobrir os homens e o sentido que atribuem ao lugar, descobrirão as comunidades e as territorialidades, desvendando as ideologias espaciais, muitas vezes remetendo ao cerne de numerosos conflitos existentes no mundo contemporâneo (KOZEL, 2002, p. 216).

Com relação ao peso da influência das relações imaginárias (ideias) sobre o processo produtivo e sobre as re- lações sociais implícitas, Godelier se questiona: "qual é a parte das idéias, do ideal, no funcionamento das relações sociais? Qual é a parte do pensamento na produção da sociedade e na sua reprodução?” (GODELIER, 1984, p. 21).

Como resposta, o autor afirma que nenhuma ação material intencional do homem sobre a natureza pode ocorrer sem que se coloque em funcionamento, desde o seu início, a intenção das realidades "ideais", as representações, os julgamentos, os princípios do pensamento. No coração das relações materiais do homem com a natureza aparece uma parte ideal onde exercem e se misturam três funções do pensamento: representar, organizar e legitimar as relações dos homens entre eles e com a natureza (GODELIER, 1984, p. 21).

Em outras palavras, trata-se de não ignorar que os indivíduos podem ter relações imaginárias com suas condições de existência, com eles mesmos e com os outros (GODELIER, 1984, p. 20): esses agricultores impõem a eles próprios uma doutrina ética de práticas concebidas como menos degradantes da natureza, assim como ao grupo como um todo com o qual partilha um território comum, vivendo em comunidades vizinhas. Em suma, essas relações imaginárias permeiam o ambiente social e biofísico das comunidades porque estão inseridos e fazem parte de uma mesma 'sociedade de interconhecimento', para usar a expressão de Mendras.

Com isso procura-se mostrar que as relações sociais dominam no momento que elas funcionam ao mesmo tempo como relações sociais de produção, como quadro e suporte do processo material de apropriação da natureza (GODELIER, 1984, p. 20).

\section{O conhecimento das práticas: a síntese das ações coletivas na produção da paisagem}

O território é o produto das ações (territorialidades, ou as identidades coletivas) dos indivíduos no ambiente. Ele é a parte material das relações que a sociedade mantém com a natureza, e a territorialidade, a parte imaterial, com

13 A fronteira entre a natureza e a cultura, a distinção entre material e o ideal tendem a se apagar quando se analisa a parte da natureza que é diretamente submetida ao homem, produzida ou reproduzida por ele (animais e plantas domésticos, ferramentas, armas, vestimentas, etc). Essa natureza exterior ao homem não é exterior à cultura, à sociedade, à história. Ela é parte da natureza transformada pela ação e assim pelo pensamento em toda sua realidade (consciente e inconsciente, individual e coletiva) do homem. Ela é realidade material e ao mesmo tempo ideal. Essa parte da natureza é natureza apropriada, humanizada, transformada em sociedade: a história inscrita na natureza (GODELIER, 1984, p. 13). 
relações sociais. O território é o chão, formas espaciais, e tem significados; produto de ações históricas que se concretizam em momentos distintos e superpostos, gerando diferentes paisagens. Essa relação território-paisagem demanda uma abordagem (i)material dessa relação, a partir da compreensão da realidade material (território) e de sua representação (paisagem) ${ }^{14}$ (SAQUET, 2007, p. 142-143).

O território rural, a partir da análise da paisagem, possui ligação com as práticas nele registradas. A paisagem torna-se, segundo essa concepção, um fator de produção agronômica do qual o agricultor é o produtor de formas e a agricultura uma "atividade sobre o meio físico que transforma as formas efêmeras em formas físicas”(DEFFONTAINES, 2001, p. 197). Trata-se também dos “fatos técnicos" ligados às práticas produtivas trabalhadas pelos agricultores e das relações que elas exercem no meio físico e biológico.

Por outro lado, Bertrand e Bertrand (2002, p. 277278) afirmam que a paisagem não é um conceito científico, não pertence a nenhuma disciplina em particular. Ela pertence ao mundo das representações, da estética e do simbólico. Objetiva ou subjetiva, real ou imaginária, sonhada ou virtual, tantas dimensões interativas que devem entrar em uma problemática renovada e que implicam em metodologias adaptadas. Ela aparece ao mesmo tempo como objeto e sujeito: ela é objeto-território na sua materialidade; ela é sujeito, nascida no olhar carregado sobre o território com sua carga emocional e toda sua profundidade humana.

Sendo assim, a paisagem é global e múltipla. O complexo território-paisagem é de alguma forma o ambiente no olhar dos homens, um ambiente com o rosto humano. Um mesmo território não se torna paisagem senão através do cruzamento de múltiplos olhares, a partir de fenômenos sensoriais e cognitivos partilhados e, portanto, o postulado que funda a análise da paisagem não pode ser senão social: é o sistema de produção no largo sentido, quer dizer, produzindo bens materiais e culturais, que, no interior de um grupo social definido e em um dado espaço, desenha o conteúdo material e cultural de uma paisagem ${ }^{15}$ (BERTRAND;
BERTRAND, 2002, p. 176).

Essa definição de paisagem se aproxima daquela defendida pela geografia cultural de Augustin Berque que concebe paisagem como 'marca' e 'matriz' da relação que uma sociedade estabelece com o espaço e com a natureza. Essa marca possui um sentido implicando toda uma cadeia de processos físicos, mentais e sociais; estes processos participam dos esquemas de percepção, de concepção e de ação - ou seja, da cultura que canalizam, em certo sentido, a relação de uma sociedade com o espaço e com a natureza, isto é, a paisagem enquanto 'matriz'. Nesse sentido, a paisagem é plurimodal (passiva-ativa-potencial) como é plurimodal o sujeito para o qual a paisagem existe: a paisagem e o sujeito são co-integrados em um conjunto unitário, que se autoproduz e se auto-reproduz' e, portanto, se transforma porque há sempre interferências. Essa relação impregnada de sentido é a cultura (BERQUE, 2004).

Buscando analisar as interações entre as paisagens e as práticas agrícolas, Jean-Pierre Deffontaines aponta para a necessidade da agronomia dialogar com outras disciplinas, compartilhando com as ciências sociais seu referencial teórico-metodológico: o estudo as representações coletivas e das percepções de cada indivíduo. $\mathrm{O}$ agricultor percebe a paisagem e constrói uma idéia a respeito dela, isto é, representando-a segundo o enfoque sócio-cultural por ele vivenciado. Há a construção simbólica da paisagem a partir de sua abordagem visual. A paisagem é, nesse sentido, vista (vue) e vivida (vécue).

Portanto, seguindo o raciocínio, torna-se necessário estudar as práticas para conhecer os projetos que guiam as escolhas de como, quanto e para que produzir, conhecendo também, no sentido inverso, os projetos para conhecer as práticas. Volta-se, então, à questão da análise das práticas, isto é, do "savoir-faire” a partir da análise das percepções e representações dos agricultores sobre seu entorno.

Abre-se, assim, uma brecha na forma de se fazer pesquisas e interpretar os fenômenos naturais. A subjetividade e os dados qualitativos passam a ser considerados nessa nova forma de se fazer ciência. A Paisagem, interpretada e valorada a partir de inúmeras perspectivas e diferentes con-

14 A retomada do conceito de paisagem após 1970, trouxe à geografia novas acepções fundadas em outras matrizes epistemológicas. Matrizes estas apoiadas simultaneamente em várias dimensões cognitivas: uma dimensão morfológica que visa entender o conjunto de formas criadas pela natureza e pela ação humana; uma dimensão histórica; uma dimensão espacial, enquanto estudo da distribuição de padrões de paisagem na superfície terrestre e suas correlações; e uma dimensão simbólica, isto é, uma noção de paisagem portadora de significados, expressando valores, crenças, mitos e utopias (CORREA; ROSENDAHL, 2004, p. 8).

15 Por grupo social os autores entendem "um conjunto de indivíduos organizados no interior de um mesmo sistema de produção, ligados entre eles por uma mesma prática da natureza e que produzem um conjunto coerente de bens materiais e culturais”. O sistema de produção agrossilvopastoral (BERTRAND; BERTRAND, 2002, p. 176). 
textos histórico-sociais, ganha um novo status científico dentro das disciplinas do universo físico-biológico e do social.

Enfatizando que o modo de se fazer ciência, baseado na importância do quantitativo está em crise e precisa ser repensado, Deffontaines (2006) sugere que a agronomia também deve ser repensada em uma nova proposta que dê importância à interpretação qualitativa dos fenômenos naturais, possibilitando com isso a inclusão das percepções e representações do próprio pesquisador, assim como das populações envolvidas nos estudos.

O espaço é, de fato, uma obra e para captar toda sua essência convém analisá-lo não apenas do aspecto exterior da paisagem ${ }^{16}$. Os valores estéticos devem ser apreciados: ritmos, massas, cores, composições. Todos esses valores têm uma significação mais profunda na intimidade e vibração das percepções, diferenciada segundo aqueles que vivem e olham o espaço. A rua, a vila, o campo e a região são um vasto "teatro popular" no qual os habitantes são os atores em uma representação cotidiana (FRÉMONT, 1999, p. 259).

O espaço vivido, em toda sua complexidade, aparece como revelador das realidades regionais em seus componentes administrativos, históricos, ecológicos, econômicos, mas também, e fundamentalmente, psicológicos. De acordo às palavras de Frémont:

[...] A região não é, pois um objeto que tem alguma realidade em si, nem o geógrafo ou outro especialista são os analistas objetivos de um universo exterior ao observador, assim como a psicologia dos homens não seria reduzida a uma racionalidade de interesses econômicos ou de adaptações ecológicas. A região se ela existe é um espaço vivido. Vista, percebida, ressentida, amada ou rejeitada, modelada pelos homens e projetando sobre eles as imagens que as modelam (FRÉMONT, 1999, p. 57-58).
Os geógrafos, e agora também os agrônomos, se interessam pelo vivido, pelo subjetivo, pelo corporal também. A geografia aprofunda a análise das paisagens, ela dá lugar ao religioso e ao normativo. Ela consagra trabalhos às representações e aos discursos. A gestão pára de ser um domínio estranho, os geógrafos partilham das explorações etnográficas e incluem em seu método os "savoir-faire” das sociedades tradicionais (CLAVAL, 2005, p. 240).

A partir da análise da percepção é possível estabelecer pontos de comparação entre o pensamento popular e o conhecimento científico e adequar a extensão a uma melhor interlocução entre agricultores e técnicos, uma vez compreendidos os processos cognitivos do produtor, o que possibilita ações participativas eficazes (HOEFLE et al., 2002, p. 9).

\section{Terroir $^{17}$ : o território da simbiose entre cultura e natureza}

O território - produto e condição social, influenciando na constituição da identidade local em virtude das ações coletivas - tem um conteúdo dinâmico e ativo, com componentes objetivos e subjetivos, nos níveis local e extralocal. Por sua vez, a territorialidade é a identidade construída coletivamente pelos sujeitos locais interagindo entre si e com o ambiente e significa uma forma para, politicamente, potencializar ações e os recurso para o desenvolvimento local. Nesse sentido, a identidade coletiva significa territorialidade ativa, como governança organização para a conquista de autonomia num sistema local territorial (SAQUET, 2007, p. 152).

Constatando que a paisagem aparece cada vez mais como uma finalidade social, parece necessário, em uma perspectiva de desenvolvimento local, dispor de métodos

16 Do final do século XIX até os anos 1970, a paisagem é apreendida do exterior, como um objeto que se pode ler segundo duas perspectivas: a primeira é funcional, posto que isso se vê reflete os processos no mundo natural e o movimento das sociedades que habitam, exploram e manejam o ambiente; a segunda é arqueológica, posto que alguns traços formados no passado subsistem ainda que as condições que lhes tinham feito nascer tenham desaparecido (CLAVAL, 2005, p. 197).

17 Em 1964, dois autores, Paul Pelissier e Gilles Sautter propuseram um estudo sistemático das estruturas agrárias da África intertropical e do Sahara (Atlas des terroir africains) cuja finalidade era representar toda a variedade das paisagens agrárias africanas, os documentos de base de uma tipologia das formas de ocupação do solo. Para tanto, definem o quadro operacional e a metodologia de monografias de terroir: “um território contínuo inteiramente submetido, segundo uma intensidade e modalidades variadas, à exploração agrícola”. Por terroir os pesquisadores também comprendem “a porção de território apropriado, gerenciado e utilizado pelo grupo que aí reside e daí tira seus meios de existência”. O termo só faz sentido na medida em que o solo é o objeto de uma exploração de caráter agrícola, cuja marca na paisagem pode ajudar grandemente a reconhecer os limites de um terroir individualizando-o em relação à natureza “desocupada” ou em relação às células rurais vizinhas (SAUTTER; PÉLISSIER, 1964, p. 57 e 58).

18 Para Deffontaines (1995, p. 164) “é a partir da observação da paisagem na escala do terroir e da parcela que a leitura do espaço pelos agrônomos é a mais 
de análise da evolução fisionômica da paisagem, e sobretudo, que inclua em suas análises:

o espaço percebido e representado, enquanto construção individual e coletiva, [...] em relação direta com o espaço da vida - com toda a sua intensidade e diversidade de práticas espaciais, onde intervém igualmente o imaginário, o sonho [isto é, os projetos das populações locais] (GUCHUMIAN, 1989, p. 34).

Nessa perspectiva crítica, Bertrand (2005) sugere o sistema tripolar GTP (Geossistema-Território-Paisagem) enquanto método para entender o fenômeno Paisagem, disponibilizando para tanto ao menos três entradas principais em um mesmo território: i) o geossistema: tratando dos objetos e dos processos biofísicos que por essência já são mais ou menos antropizados; ii) o território: que leva em conta as estruturas e os funcionamentos ligados às atividades sócio-econômicas, tendo já compreendido os dados geossistêmicos e da paisagem; e iii) a paisagem: apreendendo a dimensão sensível e simbólica através das representações sócio-culturais.

Esse recorte espacial do território da produção familiar, a partir da "análise naturalista dos geossistema antropizados e da análise sócio-cultural das representações da paisagem estão fazendo evoluir os conteúdos tradicionais do ensino agronômico". Com isso, as noções de base da agronomia tais como a potencialidade, a fertilidade, os recursos naturais podem ser reenquadradas em um dado território, restando ao agrônomo dotar-se de um instrumental territorial eficaz; um método multidimensional para apreendê-lo ${ }^{18}$ (BERTRAND, 2005, p. 31).

Considerando-se que uma região apresenta traços particulares em parte ligados à natureza de seu ambiente e que existem normas culturais também particulares (as representações próprias a cada grupo social), cada 'território da exploração agrícola’ - o terroir - é assim portador de uma imagem que associa homens e meios, por conseguinte, é entendido por Cartier (2004, p.34) como: “uma representação social da percepção de diferenças naturais [e] associá-lo à população confere a esta uma origem natural local, evidentemente mítica”.

A idéia é a de simbiose localizada e histórica entre os elementos naturais e a cultura própria a uma população que identifica as aptidões desses elementos naturais, ou seja, identificar as diferentes aptidões remete à evolução técnica que corresponde a uma adaptação renovada segundo as variações naturais, a evolução das normas sociais, econômicas e culturais. Essa dimensão integrativa do terroir, singularidade nascida das interações naturais, técnicas e culturais, serve em primeiro lugar ao propósito dos agrossistemas (CARTIER, 2004, p. 37).

Nesse sentido, pode-se dizer também que da mesma forma que o terroir é influenciado pelo savoir-faire local, este é dependente das condições naturais específicas das quais resultam a diversidade de adaptações humanas. A entidade terroir corresponde, assim, à simbiose de fatores naturais, de fatores tecnológicos e dos fatores sociais que geram essa tecnologia (CARTIER, 2004, p. 38).

Concebida como 'marca e matriz'19 - utilizando a expressão de Berque - das ações humanas sobre o espaço, a paisagem segundo Deffontaines (2006) é entendida pelo agricultor como ato de suas práticas a partir das quais ele mobiliza as proporções, as escalas, os ritmos, as cores, as sombras e as luzes. Nesse sentido, o agricultor é também produtor de formas. E se o agricultor produz formas, há também uma linguagem visual da agricultura que resulta, mais que dos processos técnicos de produção, da maneira do agricultor pensar sua atividade e a sua relação com o meio. É aí que se concretiza a independência e autonomia do agricultor em relação ao mundo do sistema racional.

Carregados de subjetividades e simbolismos, os terroirs refletem as paisagens rurais desenhadas conforme os projetos individuais e coletivos sintetizados nas ações dos movimentos sociais agroecológicos. Os entendimen-

original”. O terroir tem sido definido como uma porção do espaço que possui, portanto, uma unidade fisionômica, correspondendo a um recorte do território em unidades no seio das quais a atividade agrícola parece poder ser caracterizada por uma certa homogeneidade.

19 Essa definição de paisagem é defendida por Augustin Berque. Para o autor, a paisagem enquanto ‘marca’ e ‘matriz’ da relação que uma sociedade estabelece com o espaço e com a natureza possui um sentido que implica toda uma cadeia de processos físicos, mentais e sociais; estes processos participam dos esquemas de percepção, de concepção e de ação - ou seja, da cultura que canalizam, em certo sentido, a relação de uma sociedade com o espaço e com a natureza, isto é, a paisagem enquanto ‘matriz'. Nesse sentido, a paisagem é plurimodal (passiva-ativa-potencial) como é plurimodal o sujeito para o qual a paisagem existe: a paisagem e o sujeito são co-integrados em um conjunto unitário, que se autoproduz e se auto-reproduz’ e, portanto, se transforma porque há sempre interferências. Essa relação impregnada de sentido é a cultura (BERQUE, 2004). 
tos (concepções) de natureza derivam de um mosaico de influências que combinam diferentes tipos de saberes sobre a paisagem rural e que são filtrados e reelaborados conforme os anseios e projetos dos agricultores, tendo-se em vista que a propriedade familiar é o lugar onde reside a autonomia do(a) agricultor(a) em relação ao mundo do sistema racional.

Ora, trata-se de interpretar a configuração de territórios da agricultura familiar ecológica que se expressam como lugares alternativos aos grandes espaços "vazios e estéreis" dos commodities, valorizados sazonalmente pelo mercado e pensados de acordo com o projeto de desenvolvimento modernizador e homogeneizador para o meio rural.

\section{Considerações finais}

O recorte espacial das práticas agrícolas, ou seja, entendimento do funcionamento (organização) das relações entre as agriculturas e a natureza passa pelo estudo das

\section{Referências}

ABRAMOVAY, R. Paradigmas do capitalismo agrário em questão. São Paulo: HUCITEC/ANPOCS/Editora da UNICAMP, 1992, p. 275.

ALMEIDA, Jalcione. A Agronomia entre a teoria e a ação. Revista de Educação Agrícola Superior, Brasília, ABEAS, v. 18. n. 2, p. 7-13, 2000.

BERGAMASCO, S.; BLANC-PAMARD, C.; CHONCHOL, M-E. Pour um Atlas des assentamentos brésilièns. Reformes agraires et espaces de recherche, France: Autrepart, n. 3, p. 149-175, 1997. Disponível em: <http://www.bondy.ird.fr/ pleins_textes/>. Acesso em: 25/08/2006.

BERTRAND, G. La géoagronomie, en nouveau territoire? In: PREVOST, P. (Dir.). Agronomes et territoires. Actes du colloque. Paris: Entretiens Du Pradel, 2005. p. 25-33.

BERTRAND, C.; BERTRAND, G. Une géographie traversière: l'environnement à travers territoires et temporalités. Paris: Éditions Arguments, 2002. 330 p.

. JOLLIVET, M. Transformation du monde rural. Aspects géographiques, sociologiques et économiques. In: representações e percepções da paisagem, que se expressam materialmente no território da agricultura familiar. As paisagens configuradas pelos agricultores familiares representam um espaço de vida e trabalho, cujo emprego de tecnologias alternativas deve propiciar a reprodução deste espaço simbólico. Nesse sentido, pode-se dizer, conforme Godelier (1984) que o meio ambiente tem sempre dimensões imaginárias que dão sentido aos comportamentos e intervenções sobre a natureza. Este mosaico de influências combina diferentes tipos de saberes que reconstroem o território-paisagem rural e são reelaborados e filtrados conforme os anseios e projetos dos agricultores, tendo-se em vista que a propriedade familiar é o lugar onde reside a independência e autonomia do(a) agricultor(a) em relação ao mundo do sistema racional. Tais identidades coletivas, que são configuradas pelo duo indissociável matrizes cognitivas - práticas agrícolas, devem ser captadas em todas as dimensões co-evolutivas da relação agricultores-natureza como expressões da territorialidade na reconstrução de novos projetos alternativos de desenvolvimento territorial local, baseados em uma racionalidade ambiental substantiva.
Colloques de Marly. Sauvergarde des espaces naturels. Paris: Centre de recherche et de rencontres d'urbanisme, 1980. p. 722.

BERQUE, A. Paisagem-marca, paisagem-matriz: elementos da problemática para uma geografia cultural. In: CORREA, R.L.; ROSENDAHL, Z. (Org). Paisagem, tempo e cultura. 2. ed. Rio de Janeiro: Ed. UERJ, 2004, p. 84-91.

BEZERRA, M. C. L; VEIGA, J. E. (Coord). Agricultura Sustentável. Brasília: Ministério do Meio Ambiente/IBAMA/ Museu Emílio Goeldi, 2000, p. 190.

BILLAUD, J-P. Environnement et ruralité: enjeux et paradoxes. Desenvolvimento e Meio Ambiente: Interdisciplinaridade, Meio Ambiente e Desenvolvimento. Curitiba: Editora UFPR, n. 10, p. 111-118, 2004.

. SOUDIÈRE, M. La nature pour repenser le rural? In: JOLIVET, M.; MATHIEU, N. (Ed.). Du rural à l'environnement: la question de la nature aujourd'hui. Paris: L'Harmattan/ARF, 1989, p. 180-191.

BONIN, S. Au delà de la représentation, le paysage. Revue 
Strates-LADYSS, n. 11, p. 13-26, 2004. Disponível em: <http:/ /strates.revues.org/index.html>. Acesso em: 13/9/2006.

BRANDENBURG, A. Agricultura Familiar, ONGs e desenvolvimento sustentável. Curitiba: Editora da UFPR, 1999.

. Movimento agroecológico: trajetória, contradições e perspectivas. Desenvolvimento e Meio Ambiente: caminhos da agricultura ecológica. Curitiba: Editora da UFPR, n. 6, 2002.

. FERREIRA, A. D. D.; SANTOS, L. J. C. Dimensões sociambientais do rural contemporâneo. Interdisciplinaridade, Meio Ambiente e Desenvolvimento. Revista Desenvolvimento e Meio Ambiente. Curitiba: Editora UFPR, n. 10, p. 119-125, jul./dez. 2004.

Ciências sociais e ambiente rural: principais temas e perspectivas analíticas. Ambiente \& Sociedade, v. 8, n. 1 jan./ jun. 2005. Disponível em: <www.scielo.org>. Acesso em: 4/ 12/2006.

CARON, P. À quels territoires s'intéressent les agronomes? Les point de vue d'un géographe tropicaliste. Revue Natures Sciences Sociétés, 13, p. 145-153, 2005.

CARTIER, S. Terroirs em nuances. Revue Strates-LADYSS, n. 11, p. 13-26, 2004. Disponível em: <http://strates.revues.org/ index.html>. Acesso em: 13/9/2006.

CLAVAL, P. Épistemologie de la géogrphie. Paris: Armand Colin, 2005, p. 266.

. A revolução pós-funcionalista e as concepções atuais da geografia. In: MENDONÇA, F.; KOZEL, S. (Org.). Epistemologia da Geografia contemporânea. Curitiba: Editora UFPR, 2002. p.11-43.

CORRÊA, R. L.; ROSENDAHL, Z. (Org). Paisagem, tempo e cultura. Rio de Janeiro: EdUERJ, 2004, 123p.

DEFFONTAINES, J-P. Un cheminement entre agronomie et sciences humaines. Palestra proferida no Institute National de Recherche Agronomique (INRA) d'Ivriy, unité Mona, Paris, coordenada por Pierre Alphandéry et Sophie Bobbé, no dia 12 de maio de 2006.

Les sentiers d'un géoagronome. Paris: Éditions Arguments, 2001. 360p.

. Dynamique physionomique d'un paysage rural. Essai de modélisation de la composante agricole. Cahiers d'études et de recherches francophones / Agricultures, Paris, v. 4, n. 6, Novembre-Décembre, 1995.

DESENVOLVIMENTO E MEIO AMBIENTE. A reconstrução da ruralidade e a relação sociedade/natureza. Curitiba.
Editora UFPR, n. 2, 2000.

DUVERNOY, I. Espace agricole périurbain et politiques communales d'aménagement: l'exemple de l'aglomération albigeoise. Electronic European Journal of GeographyCybergeo, Paris, 2002. Disponível em: <http://193.55.107.45/ GEOAPPL/duvernoy/Duvernoy1.htm>. Acesso em: 21/8/ 2006.

FERREIRA, A. D. D. Processos e sentidos do rural na contemporaneidade: indagações sobre algumas especificidades brasileiras. Estudos Sociedade e Agricultura. Curitiba: Editora UFPR, n. 18, p. 28-46, 2002.

FLORIANI, D. Diálogo de saberes:uma perspectiva socioambiental. (Org): FERRARO JR. Encontros e Caminhos: formação de educadores ambientais e coletivos educadores. Brasília: MMA, DEA, 2007. v. 2, p. 106-115.

FRÉMONT, A. La région, espace vécu. 2. ed. Paris: Flammarion, 1999, 288p.

GODELIER, M. L'idéel et le matériel: pensée, économies, sociétés. Paris: Librairie Arthème Fayard, 1984. 348p.

GUMUCHIAN, H. Les répresentations em géographie. Définitions, méthodes et outils. In: Représenter l'espace. L'imaginaire spatial à l'école. Paris: Anthropos, Diff. Economica, 227 p., 1989.

GUMUCHIAN, H. Représentations et aménagement du territoire. Paris: Anthropos, Economica, 1991. 143p.

HOEFFEL, J. L.; FADINI, A. A. B.; MACHADO, M. K. ; REIS, J. C. Percepção ambiental e conflitos de uso dos recursos naturais - um estudo na APA do Sistema Cantareira. São Paulo, Brasil. In: Cambpinas: III Encontro ANPPAS, 2006.

JOLLIVET, M. Les metamorphoses d'un rural incertain. In: . Vers un rural postindustriel: rural et environnement dans huit pays européens. Paris: L’Harmattan, 1997, p. 351371.

KOZEL, S. As representações no geográfico. In: MENDONÇA, F.; KOZEL, S. (Org.). Elementos de epistemologia da geografia contemporânea. 2. ed. Curitiba: Editora UFPR, 2002. p. 215-232.

LAMARCHE, H. (Coord.). A agricultura familiar: comparação internacional. Tradução de: Angela M.N. Tijiwa.Campinas: Editora da UNICAMP, 1993. (Uma realidade multiforme, 1). . A Agricultura familiar: do mito à realidade. Campinas: UNICAMP, 1998. v. 2.

MADE. Região Metropolitana de Curitiba: Relatório Turma 
IV. Doutorado em Meio Ambiente e Desenvolvimento, Linha de pesquisa: sistemas sociais, técnicos e naturais em áreas rurais. Curitiba, 2001.

. O Rural da RMC sob o olhar interdisciplinar: relatório síntese da oficina dois. Relatório II da Turma V. Doutorado em Meio Ambiente e Desenvolvimento, Linha de pesquisa: sistemas sociais, técnicos e naturais em áreas rurais. Curitiba, 2003.

MATHIEU, N. Rural et urbaine, unité et diversité dans les évolutions des modes d'habiter. In: JOLLIVET, M.; EIZNER, N. (Dir.). L'Europe et ses campagnes. Paris: Presses de Sciences Politiques, 1996. p. 187-203.

PINHEIRO, G. S. R. Agricultor familiar e projeto agroecológico de vida. 112p. Dissertação (Mestrado em Sociologia) - Setor de Ciência Humanas, Letras e Artes, Universidade Federal do Paraná, Curitiba, 2004.

SAQUET, M.A. Abordagens e concepções de território. 1. ed. São Paulo: Expressão Popular, 2007. 200p.

VARGAS, I. Território, identidade e governança no pantanal matogrossense: um caleidoscópio da sustentabilidade complexa. $246 \mathrm{f}$. Tese (Doutorado em Meio Ambiente e Desenvolvimento) - Pró-Reitoria de Pesquisa e Pós-Graduação, Universidade Federal do Paraná, Curitiba, 2006.

WANDERLEY, M.N.B. Raízes históricas do campesinato brasileiro. XX Encontro Anual da ANPOCS. GT 17: processos sociais agrários. Caxambu, MG. outubro 1996, 18 p.

. A valorização da agricultura familiar e a reinvidicação da ruralidade no Brasil.: Revista Desenvolvimento e Meio Ambiente, n. 2, p. 29-38, 2000.

ZANONI, M. M.; FERREIRA, A. D.; MIGUEL, L. A.; FLORIANI, D.; CANALI, N. A construção de um curso de pós-graduação interdisciplinar em Meio Ambiente e Desenvolvimento: princípios teóricos e metodológicos. Desenvolvimento e Meio Ambiente: em busca da interdisciplinaridade: pesquisas urbanas e rurais. Curitiba: Ed. UFPR, 2002, p. 925.

ZONIN, W.; RUSZCZYK, J. C.; CRISPIN, J. Q.; FLORIANI, N.; ELL, E.; ALMENIDA, L. Agriculturas de base ecológica na Região Metropolitana de Curitiba e o desenvolvimento socioambiental. In: II Encontro da ANPPAS, 2004, Brasilia: III Encontro ANPPAS, 2006. 